\title{
Acute Cholangitis Associated with Ceftriaxone Therapy
}

\author{
Yasuyuki Tamai and Kazuhiko Kobayashi
}

Key words: acute cholangitis, ceftriaxone, biliary sludge

(Intern Med 52: 403-404, 2013)

(DOI: 10.2169/internalmedicine.52.9108)
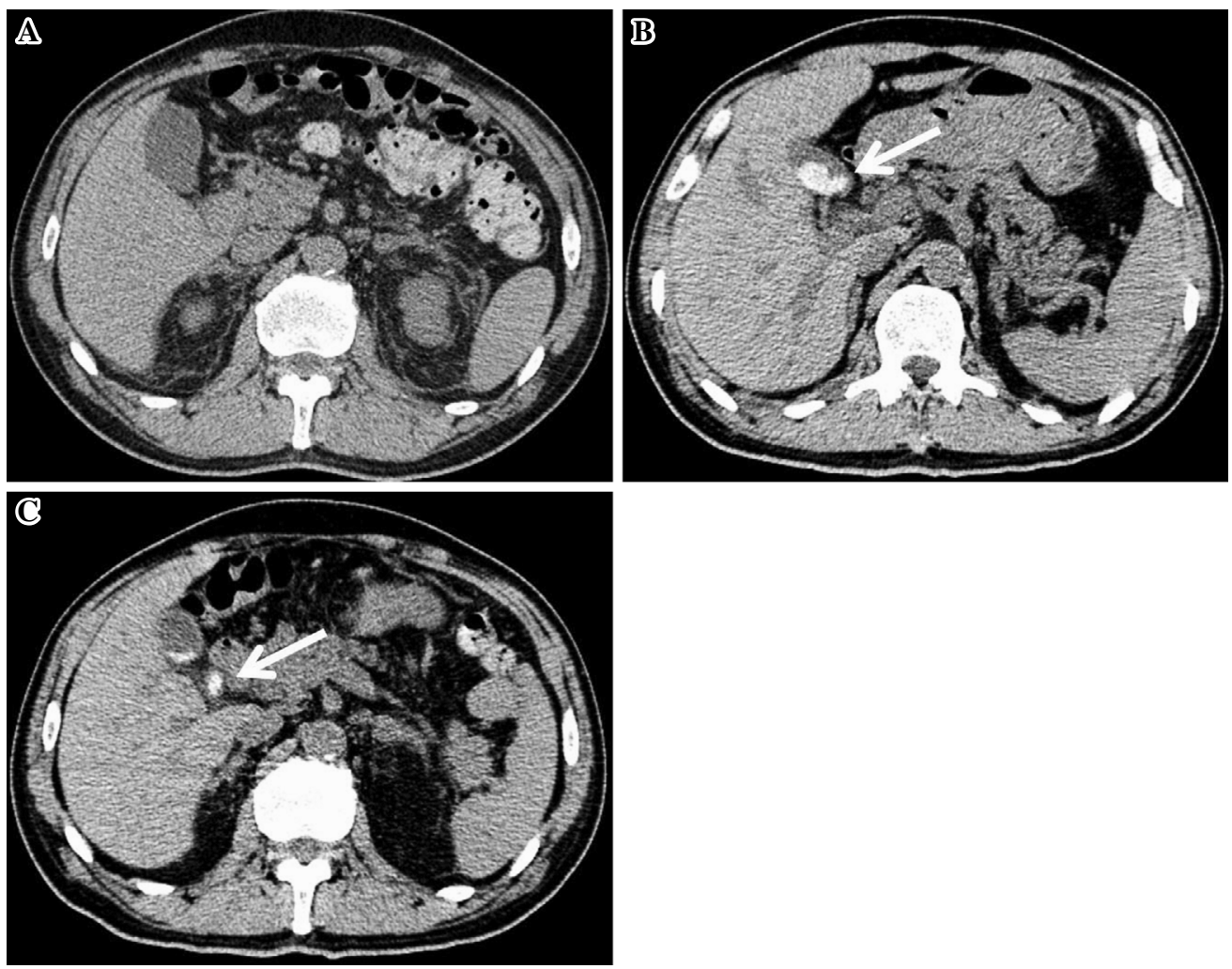

Picture.

A 57-year-old man was admitted to the hospital due to pneumonia, for which he was treated with intravenous ceftriaxone. An abdominal computed tomography scan obtained on admission did not show any gallstones (Picture A). Five days later, the patient complained of right upper quadrant pain. The blood test results revealed characteristics of acute inflammation, and abnormal liver function test findings, that is, elevated levels of serum bilirubin, alkaline phosphatase and $\gamma$-glutamyl transferase level. A reexamination showed the presence of sludge in the common bile duct (CBD) and gall bladder with CBD dilatation (Pictures $\mathrm{B}, \mathrm{C})$. The patient was found to have cholangitis and was treated with endoscopic biliary drainage. Biliary sludge is known to be a rare adverse effect of ceftriaxone therapy in neonates (1) and can lead to adverse complications such as cholangitis and pancreatitis (2). We herein report a rare case of acute cholangitis associated with ceftriaxone therapy in an adult.

The authors state that they have no Conflict of Interest (COI).

\section{References}

1. Shiffman ML, Keith FB, Moore EW. Pathogenesis of ceftriaxone- 
Intern Med 52: 403-404, 2013 DOI: 10.2169/internalmedicine.52.9108

associated biliary sludge. In vitro studies of ceftriaxone binding and solubility. Gastroenterology 99: 1772-1778, 1990.

2. Zinberg J, Chernaik R, Coman E, et al. Reversible symptomatic biliary obstruction associated with ceftriaxone pseudolithiasis. Am J Gastroenterol 86: 1251-1254, 1991.

(C) 2013 The Japanese Society of Internal Medicine http://www.naika.or.jp/imonline/index.html 